\title{
Study on the Heavy Metals Removal Efficiencies of Constructed Wetlands with Different Substrates
}

\author{
Mengzhi CHEN, Yingying TANG, Xianpo LI, Zhaoxiang YU \\ Department of Chemistry, Tongji University, Shanghai, China \\ E-mail: zxyu@mail.tongji.edu.cn \\ Received December 19, 2008; revised February 17, 2009; accepted February 20, 2009
}

\begin{abstract}
In this study constructed wetlands (CWs) were used to remove three heavy metals ( $\mathrm{Zn}, \mathrm{Cu}$ and $\mathrm{Pb}$ ). The two tested substrates were made of coke and gravel, respectively. First order dynamic model was appropriate to describe removing of $\mathrm{Zn}$ and $\mathrm{Cu}$. The experimental results showed that first dynamic removal rate constants of $\mathrm{Zn}$ in CWs with coke and gravel were $0.2326 \mathrm{~h}^{-1}$ and $0.1222 \mathrm{~h}^{-1}$, respectively. And those of Cu in CWs with coke and gravel were $0.2017 \mathrm{~h}^{-1}$ and $0.3739 \mathrm{~h}^{-1}$. However, removal efficiencies of $\mathrm{Pb}$ in the coke system and the gravel system were within 95-99\%, so the first order dynamic model failed to fit the experimental data because the hydraulic resident times of $\mathrm{Pb}$ did not affect outlet concentration of $\mathrm{Pb}$. From the removal rate constants, it is found that the coke and gravel system have different absorption efficiencies of heavy metal pollutants. Therefore, it is suggested that the removal efficiencies of heavy metals are influenced by the choice of substrates to some extent.
\end{abstract}

Keywords: Subsurface Flow Constructed Wetlands, First Order Dynamic Model, Heavy Metal Pollutant, Substrate, Removal Efficiency

\section{Introduction}

Constructed wetlands have the characteristics of excellent performance, minimal investment and operating cost, remarkable economical and social benefits in treating wastewater. In the past 30 years, Europe and North America had set up several thousand constructed wetlands, but the designs and the operations of CWs are mostly based on statistical data and the empirical formula. However, the removal mechanism of pollutants [1] is important bases of the engineering designs of the CWs, and can provide reliability of CWs in engineering design and operation.

There are a number of physical, chemical and (micro) biological processes in purification, like sedimentation, filtration, adsorption, microbial decomposition and chemical transformation [2]. Adsorption may play an important role in the removal process. Consequently, it is important to select those substrates of high ecological activity and adsorption capacity. There has been some recent work that has attempted to investigate the influence of different substrates [3,4]. But those researches mainly focus on the treatment of wastewater containing $\mathrm{P}$ and $\mathrm{N}$. There remains a lack of information on heavy metals purification effects in the CWs systems with different substrates.

The aim of this present study was to investigate the removing dynamics of three heavy metal pollutant in CWs with two substrates. Since the coke and gravel differs in their porosity, their purification efficiency may be different. In the present study two CWs (coke and gravel) were set up. The effluent was collected and analyzed for heavy metal concentrations.

With the development of the China industry, heavy metal pollution became more and more serious. Base on the investigation of Yangtze River, the best quality river of the seven rivers in China, heavy metals especially Zn, $\mathrm{Pb}, \mathrm{Cu}$ and $\mathrm{Cr}$ had polluted the water systems [5]. Considering amount of waste water containing $\mathrm{Zn}, \mathrm{Pb}$ and $\mathrm{Cu}$ mainly discharged by steel plants and copper metallurgy plants, the water pollution on $\mathrm{Pb}, \mathrm{Zn}$ and $\mathrm{Cu}$ were studied in this paper.

Plant plays an important role in CWs. Plant root zone and substrate absorb ionic heavy metal. We aimed to 
provide more data about the purification effects of CWs with different substrates. In the present study, the different heavy metals contents absorbed by plant were determined after CWs run a long time, and then the role of plant in CWs were analyzed. Finally, it is hoped that the question of stability in root zone and substrate absorption will be resolved.

The first order dynamic model, which was used to predict the removal efficiencies of the pollutants treated by CWs, should be used in the design of the CWs [2,6-8]. Though the parameter and the calculation of the equation are simple, first order dynamic model has some limitations. However it is still an appropriate equation for describing the removal mechanism of the CWs treating pollutants. In the present study, the first order model with two parameters was used to describe the removal mechanism of the different CWs.

If steady and plug flow conditions are assumed, first order dynamic model can be used to describe the reduction of pollutants. The equation can be written as:

$$
\begin{aligned}
& \frac{d C}{d t}=-k_{v} \times C \\
& \frac{d C}{d x}=-\frac{k}{q} \times C
\end{aligned}
$$

where $C$ is the concentration of the quantity concerned $(\mathrm{mg} / \mathrm{L}), t$ is the hydraulic resident time $(\mathrm{h}), k_{v}$ is volumetric rate constant $\left(\mathrm{h}^{-1}\right), x$ is the fraction of the distance through the wetland, $k$ is the areal rate constant $(\mathrm{m} / \mathrm{h})$, and $q$ is the hydraulic loading rate $(\mathrm{m} / \mathrm{h})$.

The rate constant always has two expression ways$k_{v}$ and $k$. Literature is available on $k_{v}$ with subsurface flow constructed wetland and $k$ with surface flow constructed wetland [9]. Removal rate constant represents the removal ability of the CWs. In theory, the removal rate constant relates to temperature, medium (the amount and types of microorganisms) and pollutants. Therefore, in this study the temperature was kept between $25^{\circ} \mathrm{C}-30^{\circ} \mathrm{C}$ and the removal efficiencies of three type heavy metal pollutants ( $\mathrm{Zn}, \mathrm{Cu}$ and $\mathrm{Pb}$ ) were analyzed. For the microbial membranes on the substrates were pitchy and dense, we believed the microbial membranes were steady and the microorganism were adapted to system environment. In order to compare the removal ability of different subsurface flow constructed wetlands, we established this study to determine the volumetric rate constant, $k_{v}$.

Even though there are non-degradable material in CWs, atmospheric and groundwater chemical additions, chemical speciation, and the biogeochemical cycle may generate background concentrations. Kadlec and Knight proposed a two-parameter model to describe the reduction of pollutants [2]. The equation can be written as:

$$
\frac{d C}{d t}=-k_{v}\left(C-C^{*}\right)
$$

where $C^{*}$ is the background concentration.

The key to a quantitative model of wetland operation is the determination of the volumetric rate constant, $k_{v}$. Solution of the equation then gives a linear relationship in the concentration logarithm with the residence time. The expression for the concentration logarithm at any residence time can be written as:

$$
\ln \frac{C_{o}-C^{*}}{C_{i}-C^{*}}=-k_{v} t
$$

where $C_{o}$ is the outlet concentration $(\mathrm{mg} / \mathrm{L}), C_{i}$ is the inlet concentration (mg/L).

The determination of the background concentration $C^{*}$ is the process related to each factor of the wetland and the interrelationship among them. Therefore, there is not a precise definition and a calculation method for the background concentration $C^{*}$.

Based on the above discussion, we conclude that the main source of the background concentration is the heavy metals ionic on the non-degradable materials, which is mainly the heavy metals ionic existed by physic absorption form on the substrate. In our previous research, the experiments on the wetlands at different operation periods showed that the heavy metals accounted for $0.69 \%-1.98 \%$ (coke system) and $1.07 \%$ $3.24 \%$ (gravel system) of the heavy metal intercepted by the wetlands, respectively. With the operation time of the wetlands increasing, the heavy metals stripped from the wetland would increase. In other words, the background concentration isn't constant, but changes little with the operation time increasing. If the total amount of the heavy metal intercepted by the wetland can be calculated, the expression for the background concentration can be written:

$$
\begin{aligned}
& C^{*}=0.69 \% \sim 1.98 \%(w t) \quad(\text { for Coke system) } \\
& C^{*}=1.07 \% \sim 3.24 \%(w t)(\text { for Gravel system) }
\end{aligned}
$$

\section{Materials and Methods}

\subsection{Process Description}

The wetlands, located in Tongji University of Shanghai, were constructed in 2007. Two wetlands, shown in Figure 1 , are filled with two different substrates (coke and gravel) with a packed bed size of $1930 \mathrm{~mm} \times 400 \mathrm{~mm} \times 600 \mathrm{~mm}$ $(\mathrm{L} \times \mathrm{W} \times \mathrm{H})$. PVC rectangular sink with volume of $0.6 \mathrm{~m}^{3}$ was used for storing cistern. Structural slope is $1 \%$ of height of wetland. 

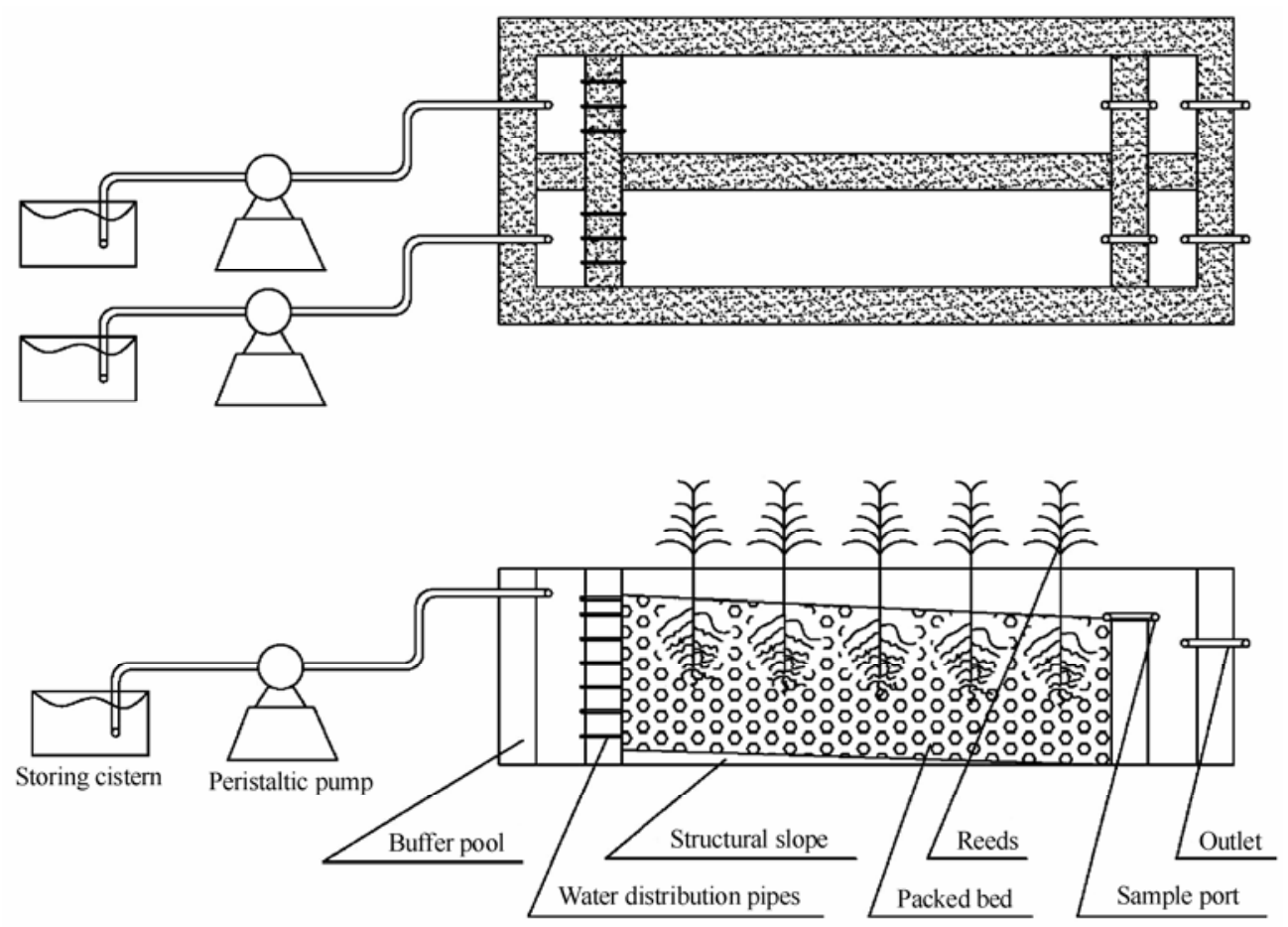

Figure 1. Flow chart of the subsurface flow constructed wetlands.

In order to compare with the treating effect of different substrates, coke with particle diameter of 5-10 mm and gravel with particle diameter of 3-8 mm were packed in the different CWs, respectively. The porosity of coke wetland and gravel wetland were 0.43 and 0.36 .

Activated sludge was obtained from secondary sedimentation basin in Shanghai Quyang sewage treatment plant. Because reeds have a much better absorption of heavy metals than other species of plants $[10,11]$, the reeds with height of $1.7 \mathrm{~m}$ and density of $60 \mathrm{plant} / \mathrm{m}^{2}$ are used in the experiment.

Wastewater flowed into constructed wetland by Lange peristaltic pump with a model of BT00-300M, speed of $0-300 \mathrm{r} / \mathrm{min}$ and a transport regulation range of $0.07-$ $1140 \mathrm{ml} / \mathrm{min}$. In order to make the inflow well distributed and close to the ideal flow patterns, the water distribution pipes, shown in Figure 2, are alternately permutated. The heavy metal wastewater was lifted into the buffer tank by peristaltic pump, and then flowed into the constructed wetlands through the water distribution pipes. After being treated by the CWs, the heavy metal wastewater flowed out of the system through the sampling pipe and outlet pipe.

After the constructed wetland run for a long time, we collected reeds from inlet, medial position and outlet of constructed wetlands. First, the reeds were cleaned, and cut into seven parts. Secondly, the samples were put into crucible, dried at $70^{\circ} \mathrm{C}$ at baking oven for constant weight, and weighted in turn. Thirdly, the samples were incinerated about 40min, put into muffle furnace to heat for $2 \mathrm{~h}$ at $600^{\circ} \mathrm{C}$, treated in the processes of nitric acid hydrolysis, extraction and dilution. Finally, the samples were detected, and the heavy metals contents in reeds were determined by atomic absorption spectrometry [12].

\subsection{Experiment Reagents}

Heavy mental wastewater for experiment was got by Adding heavy metal salts in the water. Copper sulfate, lead nitrate and zinc sulfate are used as heavy metal pollutants. The experiment reagents and their specifications are listed in Table 1.

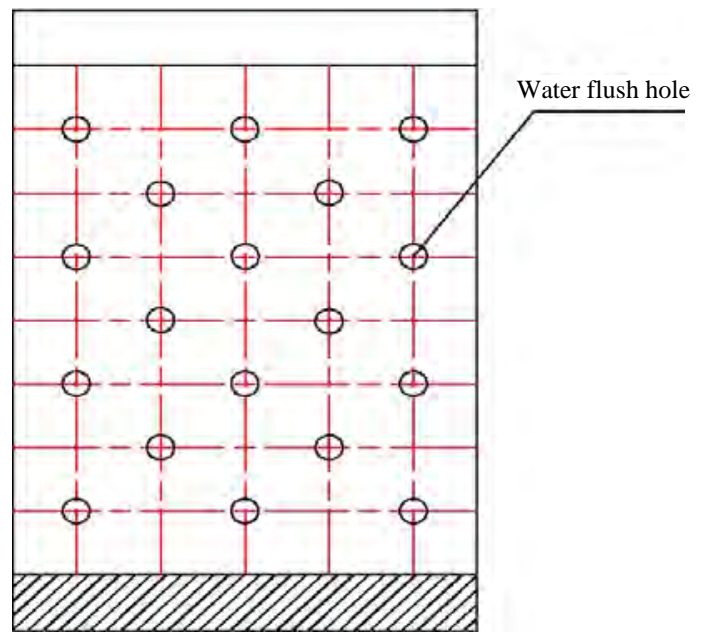

Figure 2. Drawing of water distribution system. 
Table 1. Experiment reagents and their specifications.

\begin{tabular}{llll}
\hline \multicolumn{1}{c}{ reagents } & \multicolumn{1}{c}{ specifications } & \multicolumn{1}{c}{ reagents } & specifications \\
\hline sucrose & \multicolumn{1}{c}{ eatable } & magnesium sulfate & analytically pure \\
anhydrous sodium carbonate & analytically pure & potassium dihydrogen phosphate & analytically pure \\
ammonium chloride & chemically pure & potassium chloride & analytically pure \\
copper sulfate & analytically pure & lead nitrate & chemically pure \\
zinc sulfate & analytically pure & lead nitrate & analytically pure \\
zinc oxide & reference reagent & hydrochloric acid & analytically pure \\
\hline
\end{tabular}

The reference standards for experiment reagents and their specifications are on the GB7475-87 standards for the reagents.

\subsection{Experiment Methods and Instruments}

The experiment determination standards were concentration of $\mathrm{Cu}, \mathrm{Zn}, \mathrm{Pb}, \mathrm{pH}$, and water temperature. The preparation of the heavy metals analyses for $\mathrm{Cu}, \mathrm{Zn}$ and $\mathrm{Pb}$ was carried out according to China national standards GB7475-87 designed for heavy metals. The concentration of the heavy metals were detected by atomic absorption spectrophotometer (Agilent). The analyzing methods and instruments for determining water temperature according to State Environmental Protection Administration [13] approved methodology were water and exhausted water monitoring analysis method, and mercurial thermometer. According to China national standards GB6920-86, acidimeter was used to measure $\mathrm{pH}$.

\section{Results}

\subsection{Removal Efficiencies of $\mathbf{P b}$}

Based on results over 4 months (September-December
2007) the removal efficiencies of wetlands treating wastewater containing $\mathrm{Pb}$ were calculated. The results are listed in Table 2 and Table 3. It is clearly shown in Table 2 and Table 3 that both coke and gravel systems have remarkable removal efficiencies on treating wastewater containing $\mathrm{Pb}$. It was found that the removal efficiencies of the coke system and the gravel system were within 95-99\%. The data of those two systems treating Pb had well agreement with the zero order dynamic model rather than the first order dynamic model. It is suggested that the $\mathrm{Pb}$ removal efficiencies were mainly determined by the $\mathrm{Pb}$ concentrations, but with little relation to hydraulic resident times.

\subsection{Removal Efficiencies of Zn}

The data for the events of September-December 2007 are listed in Table 4 and Table 5. According to the Equation (5) and Equation (6), the concentrations of $\mathrm{Zn}$ were calculated. The results are shown in Figure 3 and Figure 4. It is evident from the figures that the data follow the linear shape predicted by Equation (4). The $k_{v}$ values, for the coke system and gravel system treating wastewater containing $\mathrm{Zn}$ were calculated and the results were $0.2326 \mathrm{~h}^{-1}$ and $0.1222 \mathrm{~h}^{-1}$, respectively.

Table 2. Inlet concentrations, outlet concentrations and removal efficiencies of the coke system treating the wastewater containing $\mathrm{Pb}$ at the different hydraulic loadings.

\begin{tabular}{lccccc}
\hline Hydraulic resident time (h) & 12.68 & 10.72 & 7.99 & 5.73 & 4.76 \\
\hline Inlet concentration (mg/L) & 27.44 & 23.46 & 19.48 & 21.87 & 11.53 \\
Outlet concentration (mg/L) & 0.0928 & 0.0795 & 0.2651 & 0.2883 & 0.5726 \\
Removal efficiency (\%) & 99.66 & 99.66 & 98.64 & 98.68 & 95.03 \\
\hline
\end{tabular}

Table 3. Inlet concentrations, outlet concentrations and removal efficiencies of the gravel system treating the wastewater containing $\mathbf{P b}$ at the different hydraulic loadings.

\begin{tabular}{lccccc}
\hline Hydraulic resident time (h) & 9.60 & 7.02 & 5.77 & 4.76 & 6.0 \\
\hline Inlet concentration (mg/L) & 49.890 & 40.370 & 47.009 & 47.957 & 43.152 \\
Outlet concentration (mg/L) & 0.234 & 0.394 & 0.390 & 0.596 & 0.587 \\
Removal efficiency (\%) & 99.53 & 99.02 & 99.17 & 98.76 & 98.64 \\
\hline
\end{tabular}


Table 4. Inlet concentrations, outlet concentrations and removal efficiencies of the coke system treating the wastewater containing $\mathrm{Zn}$ at the different hydraulic loadings.

\begin{tabular}{lccccc}
\hline Hydraulic resident time (h) & 12.68 & 10.72 & 5.73 & 4.76 & 4.67 \\
\hline Inlet concentration (mg/L) & 48.50 & 21.264 & 26.37 & 17.859 & 31.477 \\
Outlet concentration (mg/L) & 4.276 & 2.218 & 6.583 & 5.553 & 4.712 \\
Removal efficiency (\%) & 91.18 & 89.57 & 75.03 & 68.91 & 85.03 \\
\hline
\end{tabular}

Table 5. Inlet concentrations, outlet concentrations and removal efficiencies of the gravel system treating the wastewater containing $\mathrm{Zn}$ at the different hydraulic loadings.

\begin{tabular}{lcccccc}
\hline Hydraulic resident time (h) & 9.60 & 7.02 & 6.0 & 5.77 & 4.76 & 3.20 \\
\hline Inlet concentration (mg/L) & 5.268 & 7.439 & 5.622 & 4.603 & 5.445 & 7.218 \\
Outlet concentration (mg/L) & 2.024 & 2.526 & 2.543 & 2.478 & 1.401 & 2.558 \\
Removal efficiency (\%) & 61.57 & 66.04 & 54.77 & 46.17 & 74.26 & 64.55 \\
\hline
\end{tabular}

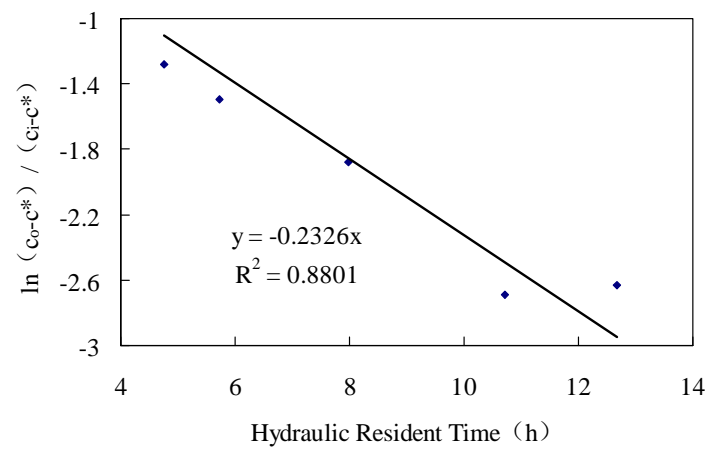

Figure 3. First-order model fitting drawing of the coke system treating $\mathrm{Zn}$.

\subsection{Removal Efficiencies of $\mathrm{Cu}$}

The data for the event of September-December 2007 are listed in Table 6 and Table 7. According to the Equation (5) and Equation (6), the concentrations of $\mathrm{Cu}$ were calculated. The results are shown in Figure 5 and Figure 6.

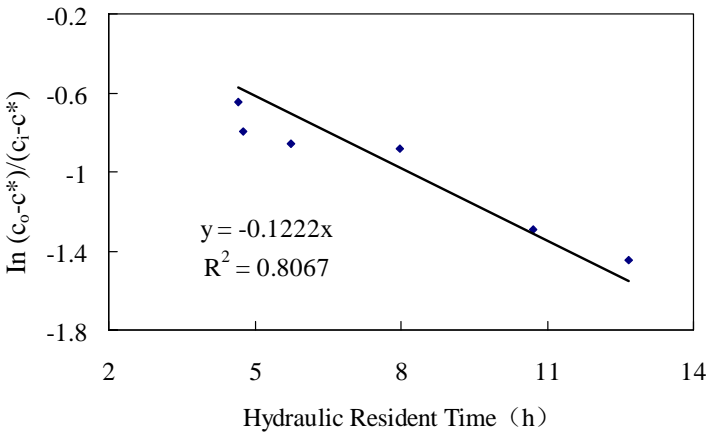

Figure 4. First-order model fitting drawing of the gravel system treating $\mathbf{Z n}$.

It is evident from the figures that the data follow the linear shape predicted by Equation (4). The $k_{v}$ values, for the coke system and gravel system treating wastewater containing $\mathrm{Cu}$ were calculated and the results were $0.2017 \mathrm{~h}^{-1}$ and $0.3739 \mathrm{~h}^{-1}$, with coefficient of correlation $\mathrm{R}^{2} 0.8801$ and 0.8067 , respectively.

Table 6. Inlet concentrations, outlet concentrations and removal efficiencies of the coke system treating the wastewater containing $\mathrm{Cu}$ at the different hydraulic loadings.

\begin{tabular}{lccccc}
\hline Hydraulic resident time (h) & 12.68 & 10.72 & 5.73 & 4.76 & 4.67 \\
\hline Inlet concentration (mg/L) & 28.519 & 26.189 & 23.666 & 18.036 & 19.783 \\
Outlet concentration (mg/L) & 2.639 & 3.198 & 5.413 & 5.269 & 6.345 \\
Removal efficiency (\%) & 90.75 & 87.79 & 77.10 & 70.79 & 67.93 \\
\hline
\end{tabular}

Table 7. Inlet concentrations, outlet concentrations and removal efficiencies of the gravel system treating the wastewater containing $\mathrm{Cu}$ at the different hydraulic loadings.

\begin{tabular}{lccccccc}
\hline Hydraulic resident time (h) & 9.60 & 7.02 & 5.77 & 4.76 & 3.34 & 3.20 \\
\hline Inlet concentration (mg/L) & 26.515 & 27.412 & 26.515 & 24.006 & 26.515 & 28.327 \\
Outlet concentration (mg/L) & 0.0735 & 2.268 & 2.577 & 0.0372 & 1.830 & 4.982 \\
Removal efficiency (\%) & 99.72 & 91.73 & 90.28 & 99.84 & 93.10 & 82.40 \\
\hline
\end{tabular}




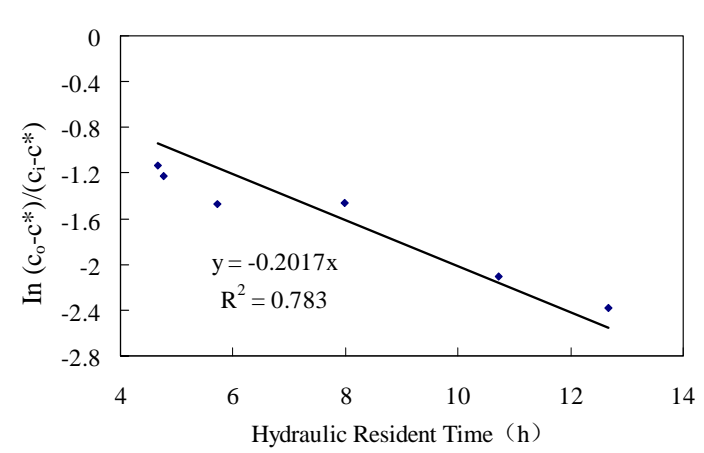

Figure 5. First-order model fitting drawing of the coke system treating $\mathrm{Cu}$.

Both the coke CWs and gravel CWs had good treatment effect on $\mathrm{Pb}$. The results showed that the treatment efficiencies for $\mathrm{Pb}$ didn't fit for first order dynamic model. The removal efficiencies of $\mathrm{Pb}$ didn't change with the increasing of hydraulic retention time. The volumetric rate constants $\left(k_{v}\right)$ for the heavy metals ( $\mathrm{Zn}$ and $\mathrm{Cu}$ ) under consideration were determined by fitting lines to the observation (Table 8).

\subsection{Heavy Metals Contents in Reeds}

The heavy metals contents of reeds are given in Figure 7. From the analysis of the three heavy metals, it is found that $\mathrm{Cu}, \mathrm{Zn}$ and $\mathrm{Pb}$ contents in reeds of coke system were $0.1667 \%, 0.2094 \%$ and $0.2781 \%$, respectively, and $\mathrm{Cu}$, $\mathrm{Zn}$ and $\mathrm{Pb}$ contents in reeds of gravel system were

Table 8. First-order model parameters of different substrates treating different heavy metal.

\begin{tabular}{ccccc}
\hline $\begin{array}{c}\text { first order } \\
\text { dynamic model }\end{array}$ & substrate & $\begin{array}{c}\text { Heavy } \\
\text { metal }\end{array}$ & $\mathrm{R}^{2}$ & $k_{V}\left(\mathrm{~h}^{-1}\right)$ \\
\hline \multirow{2}{*}{$\frac{c_{o}-c^{*}}{c_{i}-c^{*}}=-k_{V} \times t$} & coke & $\mathrm{Zn}$ & 0.8801 & 0.2326 \\
& & $\mathrm{Cu}$ & 0.7830 & 0.2017 \\
& gravel & $\mathrm{Zn}$ & 0.8067 & 0.1222 \\
& & $\mathrm{Cu}$ & 0.7149 & 0.3739 \\
\hline
\end{tabular}

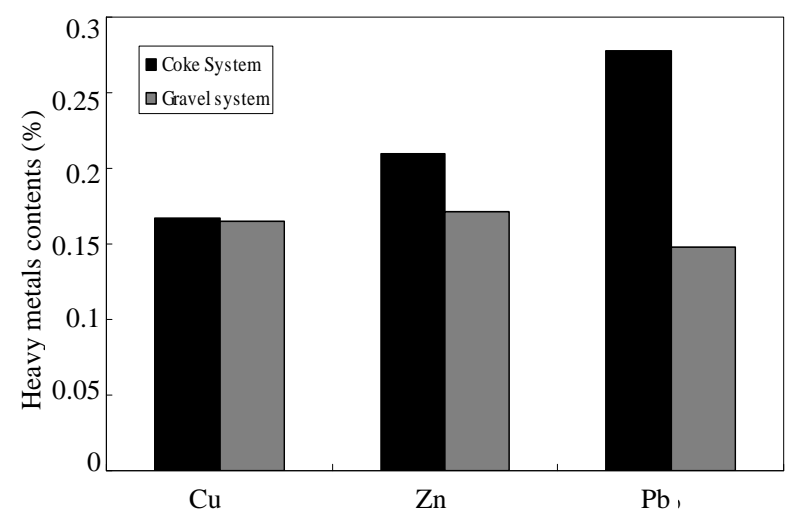

Figure 7. Heavy metals contents in reeds of different CWs based on analysis over all samples.

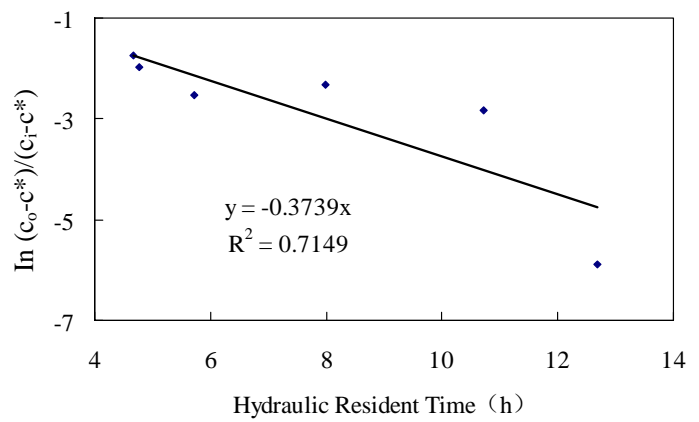

Figure 6. First-order model fitting drawing of the gravel system treating $\mathrm{Cu}$.

$0.1645 \%, 0.1713 \%$ and $0.1477 \%$, respectively. The results showed that the heavy metals contents in reed were very few. It is indicted that the reeds didn't have obvious effect on the process of CWs treating heavy metal.

\section{Discussion}

The removal efficiencies for $\mathrm{Pb}$ are higher than the efficiencies for $\mathrm{Zn}$ and $\mathrm{Cu}$. These results well agree with the discovery of Walker and Hurl [14]. The same constructed wetland has different rate constants because of the different heavy metals. The results showed that the coke system treating the $\mathrm{Zn}$ and $\mathrm{Cu}$ didn't have significant differences in the volumetric rate constant. But the volumetric rate constants of the gravel system treating $\mathrm{Cu}$ were higher than those of $\mathrm{Zn}$. The $\mathrm{Cu}$ and $\mathrm{Zn}$ contents of reeds in gravel system didn't have significant differences. It is indicated that the CWs with gravel had better purification effect on $\mathrm{Cu}$ than that on $\mathrm{Zn}$.

In the present study, the effects of the two different substrate systems were also investigated. Xu and Zhou found that different substrates had influence in constructed wetland treating heavy metals [3]. The results agree well with the finding of $\mathrm{Xu}$ and Zhou. The $k_{v}$ value of the coke system treating $\mathrm{Zn}$ is higher than that of the gravel system. The $k_{v}$ value of the coke system treating $\mathrm{Cu}$ is lower than that of the gravel system.

The results indicated that the first order dynamic model had its limitations, for the reason that it can't accurately describe all the heavy metal behaviors in the constructed wetland.

\section{Conclusions}

The study has been carried out in two constructed wetlands of different substrates (coke and gravel). The study was aimed to determine volumetric rate constants of two different substrates constructed wetlands and compared the removal ability of the different substrates. The volumetric rate constants of the coke system treating $\mathrm{Zn}$ and 
$\mathrm{Cu}$ were calculated as $0.2326 \mathrm{~h}^{-1}$ and $0.2017 \mathrm{~h}^{-1}$. The volumetric rate constants of the gravel system treating $\mathrm{Zn}$ and $\mathrm{Cu}$ were calculated as $0.1222 \mathrm{~h}^{-1}$ and $0.3739 \mathrm{~h}^{-1}$. The volumetric rate constants of the different substrates system treating heavy metal varied. The different substrate may affect the removal ability of the constructed wetland.

This study showed that the first order dynamic model did not fit for all the heavy metals retention. The first order dynamic model could predict the $\mathrm{Zn}$ and $\mathrm{Cu}$ concentration. However, this model fail to predict $\mathrm{Pb}$ concentration. Both the $\mathrm{Pb}$ removal efficiencies of the coke system and the gravel system were within 95-99\% suggesting that $\mathrm{Pb}$ retention had little relation to hydraulic resident times. In addiction, the $\mathrm{Zn}$ and $\mathrm{Cu}$ removal efficiencies of the coke system and the gravel system were within $54-91 \%$, and $69-99 \%$ suggesting that the removal efficiencies for $\mathrm{Pb}$ are higher than the efficiencies for $\mathrm{Zn}$ and $\mathrm{Cu}$.

\section{References}

[1] D. B. Kosolapov, P. Kuschk, M. B. Vainshtein, A. V. Vatsourina, A. Wiessner, M. Kastner, and P. A. Muller, "Microbial processes of heavy metal removal from carbon-deficient effluents in constructed wetlands," Engineering in Life Sciences, Vol. 4, No. 5, pp. 403-411, October 2004.

[2] R. H. Kadlec and R. L. Knight, "Treatment wetlands," CRC Press, 1996.

[3] L. H. Xu and Q. Zhou, "Study on purification ability of artificial wetlands with different filler," Shanghai Environmental Science, Vol. 21, No. 10, pp. 603-605, October 2002.

[4] C. A. Prochaska, A. I. Zouboulis, and K. M. Eskridge, "Performance of pilot-scale vertical-flow constructed wetlands, as affected by season, substrate, hydraulic load and frequency of application of simulated urban sewage,”
Ecological Engineering, Vol. 31, No. 1, pp. 57-66, September 2007.

[5] China State Environmental Protection Administration, "2000 report on the state environment in China," Environmental Education, No. 4, pp. 46-47, April 2000.

[6] R. H. Kadlec, “Overview: Surfaceflow constructed wetlands,” Water Science and Technology, Vol. 32, No. 3, pp. 1-12, 1995.

[7] R. H. Kadlec, "Deterministic and stochastic aspects of constructed wetland performance and design," Water Science and Technology, Vol. 35, No. 5, pp. 149-156, 1997.

[8] D. P. L. Rousseau, P. A. Vanrolleghem, and N. D. Pauw, "Model-based design of horizontal subsurface flow constructed treatment wetlands: A review," Water Research, Vol. 38, No. 6, pp. 1484-1493, March 2004.

[9] A. L. Simi and C. A. Mitchell, "Design and hydraulic performance of a constructed wetland treating oil refinery wastewater," Water Science and Technology, Vol. 40, No. 3, pp. 301-307, 1999.

[10] S. D. Huang and B. Leng, "The technique of man-made wetland treatment system," Sichuan Environment, Vol. 12, No. 2, pp. 48-51, 1993.

[11] Y. X. Yao and Y. J. Wang, "Application of man-made wetland in the treatment of mine wastewater," Hunan nonferrous metals, Vol. 21, No. 4, pp. 26-29, August 2005.

[12] N. H. Ince, N. Dirilgen, I. G. Apikyan, G. Tezcanli, and B. Ustun, "Assessment of toxic interactions of heavy metals in binary mixtures: A statistical approach,” Archives Environmental Contamination and Toxicology, Vol. 36, No. 4, pp. 365-372, March 1999.

[13] China State Environmental Protection Administration, Ed., "Water and exhausted water monitoring analysis method," China Environmental Science Press, 2002.

[14] D. J. Walker and S. Hurl, "The reduction of heavy metals in a stormwater wetland," Ecological Engineering, Vol. 18, No. 4, pp. 407-414, March 2002. 